(C) <2019>. This manuscript version is made available under the CC-BY-NC-ND 4.0 license http://creativecommons.org/licenses/by-nc-nd/4.0/

The definitive publisher version is available online at https://doi.org/ 10.1016/j.wombi.2018.06.020 


\section{THE EXPERIENCE OF VASA PRAEVIA FOR AUSTRALIAN MIDWIVES: A QUALITATIVE STUDY}

Background: Vasa praevia can cause stillbirth or early neonatal death if it is not diagnosed antenatally and managed appropriately. Experiencing undiagnosed vasa praevia during labour is challenging and traumatic for women and their care providers. Little is known about the experiences of midwives who care for these women.

Aim: To investigate the experience of Australian midwives caring for women with undiagnosed vasa praevia during labour and birth.

Methods: A qualitative descriptive study was conducted with midwives in Australia who had cared for at least one woman with vasa praevia during 2010-2016. Semi-structured in-depth telephone interviews were conducted and analysed using thematic analysis.

Findings: Twelve of the 20 midwives interviewed were involved in a neonatal death and/or near-miss due to vasa praevia. There was one over-arching theme, which described the 'devastating and dreadful experience' for the midwives. This had two inter-related categories of feeling the personal impacts and addressing the professional processes. Feeling scared, shocked, and guilty described how the experience took its toll on the midwives personally. The professional processes included working in organised chaos; feeling for the parents; finding communication to be hard; and, doing their best to save the baby.

Discussion: Caring for women who experienced ruptured vasa praevia had a profound impact on the emotional and professional well-being of midwives even when the baby survived. 
Javid N, Hyatt J, Homer CSE. (2019) The experience of vasa praevia for Australian midwives: A qualitative study. Women and Birth. 32 (2), pp. 185 - 192.

Conclusion: Ruptured vasa praevia was recognised as a traumatic experience that warrants serious considerations from maternity care providers, managers and policy makers. Midwives should be supported and adequately prepared to cope with traumatic events.

\section{Statement of Significance}

\section{Problem or Issue}

Vasa praevia is a recognised cause of stillbirth, early neonatal death and neonatal morbidity. Little is known about the experience of midwives caring for women with undiagnosed vasa praevia.

\section{What is Already Known}

Being involved in traumatic birth including stillbirth, neonatal death, and neonatal near-miss is associated with post-traumatic stress disorder in midwives.

\section{What this Paper Adds}

Caring for women who experienced neonatal death or a 'near-miss' event due to vasa praevia was a devastating experience that negatively impacted midwives both emotionally and professionally. The findings demonstrate the need for identification of vasa praevia during pregnancy, and supporting midwives to improve maternity care in this important area. 
Javid N, Hyatt J, Homer CSE. (2019) The experience of vasa praevia for Australian midwives: A qualitative study. Women and Birth. 32 (2), pp. 185 - 192.

\section{Introduction}

The birth of a baby is considered a joyful event. Midwives work in partnership with women aiming to provide safe, woman-centred maternity care that results in birth of a healthy baby. Midwives also work with women who face pregnancy and birth complications and provide support and care through difficult times including stillbirth and neonatal death.

Vasa praevia is a pregnancy complication with a reported incidence of 1 in 5000 births, although known to be under-reported (Sullivan et al. 2017). It is associated with a high rate of perinatal mortality (60\%) if it is not diagnosed during pregnancy (Oyelese et al. 2004). The condition occurs when the baby's blood vessels that are not protected by the umbilical cord or placenta run over or close to the cervix (Bronsteen et al. 2013). These vessels may rupture during labour causing fetal haemorrhage that can lead to intrapartum stillbirth (Bronsteen et al. 2013; Oyelese et al. 2004; Sullivan et al. 2017). Babies who are live-born may survive following aggressive resuscitation and/or blood transfusion (near-miss), or experience significant morbidity and die soon after birth (early neonatal death) (Bronsteen et al. 2013; Oyelese et al. 2004; Sullivan et al. 2017).

Diagnosis during pregnancy using transvaginal and colour Doppler ultrasound has been shown to be accurate (Ruiter et al. 2015), and significantly improves perinatal outcomes by facilitating early elective caesarean section before the onset of labour (Bronsteen et al. 2013; Oyelese et al. 2004; Sullivan et al. 2017). The majority of women with vasa praevia (83-95\%) have one or more risk factors for this condition including velamentous cord insertion, low lying placenta, succenturiate lobe placenta, in vitro fertilization, and multiple pregnancy (Ruiter et al. 2016; Sullivan et al. 2017). In 2016, Royal Australian and New Zealand College of Obstetricians and Gynaecologist (RANZCOG) recommended screening pregnant women with any of these risk factors, and elective caesarean section by 35 weeks for those who have confirmed diagnosis of vasa praevia in the third trimester (RANZCOG 2016). More recently, Sullivan et al. in the first Australian national prospective population-based study of vasa praevia reported that none of the 58 
Javid N, Hyatt J, Homer CSE. (2019) The experience of vasa praevia for Australian midwives: A qualitative study. Women and Birth. 32 (2), pp. $185-192$.

women with antenatal diagnosis of vasa praevia experienced perinatal death, but 2 out of 5 babies born to women with no antenatal diagnosis died (Sullivan et al. 2017).

Currently screening for vasa praevia is not routinely undertaken nationally or internationally (RANZCOG 2016; RCOG 2011), therefore some women may not have had a formal ultrasound-based diagnosis prior to labour and may have been clinically asymptomatic during pregnancy and prior to rupture of membranes and/or labour. In Australia, feelings of shock, horror, and trauma have been reported in women who did not have antenatal diagnosis but experienced ruptured vasa praevia during labour that led to the death of their baby or the need for aggressive resuscitation (Javid et al. 2014). Midwives who care for these women are likely to be challenged by this unexpected experience. There is little known of the experience of midwives during and after providing care for women with undiagnosed vasa praevia. Previous studies on the experiences of midwives involved in traumatic birth, stillbirth and neonatal death due to a range of reasons report feelings of anger, distress, guilt, self-blame, vulnerability, post-traumatic stress disorder (PTSD), and secondary traumatic stress (Beck, LoGiudice \& Gable 2015; Leinweber et al. 2017; Schrøder et al. 2016; Sheen, Spiby \& Slade 2015; Wahlberg et al. 2017). It is possible that midwives feel the same with the experience of caring for women with undiagnosed vasa praevia who experience a perinatal death or 'near-miss' event.

The aim of this study therefore was to explore the experience of midwives caring for women with undiagnosed vasa praevia during labour and birth, and the events that led to neonatal death or near-miss.

\section{Methods}

This study is part of a larger project about vasa praevia from the perspective of maternity care providers. A qualitative descriptive study was conducted as it provides a narrative of the events in the social process as experienced by the participants (Sandelowski 2000). Qualitative descriptive studies enable researchers to gain a thorough 
Javid N, Hyatt J, Homer CSE. (2019) The experience of vasa praevia for Australian midwives: A qualitative study. Women and Birth. 32 (2), pp. $185-192$.

understanding of associated phenomena, especially in areas that have not been studied previously (Sandelowski 2000).

\subsection{Recruitment of participants}

Midwives were recruited from the Australian maternity system. In Australia, maternity care is provided through public and private health insurance, mainly by public and private hospitals. In 2015, the majority (97\%) of the Australian women gave birth in hospitals (vs 2.1\% who gave birth in birth centres or at home) (AIHW 2015). Of those, $73 \%$ gave birth in public and $27 \%$ gave birth in private hospitals. Midwives were selected from both public and private hospitals across Australia to provide a wide range of perspectives.

Midwives were invited to participate if they were practising in Australia and had cared for at least one woman with vasa praevia during the period 2010-2016. Midwives were originally recruited through the Australian College of Midwives (ACM). An email was sent to all ACM members ( $n=5,000)$ in April 2016 inviting those who were eligible and interested in participating to contact the first author. A reminder email was sent in May 2016. Recruitment was also facilitated by Perinatal Society of Australia and New Zealand newsletter, which was emailed to their members $(n=549)$ including 61 midwives. An email was also sent to members of the New South Wales Clinical Midwife Consultants Network $(n=20)$. In addition, recruitment used social media through the closed Facebook groups of Midwifery Group Practice in Australia (1,998 members) and the Advanced Life Support in Obstetrics ( 80 members). Interested midwives contacted the first author to receive more information and organise a time for interview.

\subsection{Ethical considerations}

Ethics approval was received by the University of Technology Sydney Human Research Ethics committee (Reference number: ETH15-0137). Participants were informed about the sensitivity of the research topic including that they could stop the interview anytime if felt distressed, in which case the interview could be re-started, re-scheduled or finished based on the participant's preference, and that the researcher would discuss 
Javid N, Hyatt J, Homer CSE. (2019) The experience of vasa praevia for Australian midwives: A qualitative study. Women and Birth. 32 (2), pp. 185 - 192.

possible avenues for support if necessary. Data collection commenced after receiving signed written consent from the participants. The researcher received support from the supervisory team (co-authors) as data collection was a highly emotive experience.

\subsection{Data collection}

One-to-one interviews were conducted by telephone during May to October 2016 by the first author. Telephone interviews were selected as this enabled midwives across Australia to be interviewed on a sensitive topic by providing more flexibility, convenience and privacy for the interviewees (Drabble et al. 2016). Despite some concerns regarding developing a trusting relationship during telephone interviews in qualitative research, the interviewer was a midwife who could relate to the professional identity and experiences of the midwives. Having an insider knowledge and talking with the participants prior to the actual interview enabled building rapport with the participants to facilitate disclosure and gather rich data (Burns et al. 2012; Drabble et al. 2016).

Semi-structured in-depth interviews were based on an interview guide (Box 1) although flexible to respond to the participants. Data collection continued until no new theme was forthcoming and data saturation was reached (Charmaz 2006). Interviews lasted between 37-70 minutes (mean 50 minutes), were digitally recorded and transcribed verbatim.

\subsection{Data analysis}

Thematic analysis was concurrent with data collection and used an inductive approach following the steps described by Braun and Clarke (Braun \& Clarke 2006). Interviews were listened to, and transcripts were read several times. Originally, a mind map was developed with initial modes named by analysing four interviews line-by-line with detailed memos for each of the interviews. A coding framework was built from the initial analysis. All interviews were then coded using the framework and entered into QSR International's NVivo 11 Software. 
Javid N, Hyatt J, Homer CSE. (2019) The experience of vasa praevia for Australian midwives: A qualitative study. Women and Birth. 32 (2), pp. 185 - 192.

Short memos were written for each interview. If any new issues were identified that were outside the coding framework, these were added to build up a deep understanding of the midwives' experiences. Finally, as a cross-check, line-by-line coding was undertaken of all transcripts to ensure all aspects were captured. Due to the intense nature of the experiences, an analysis of the individual incidents, - as described by Charmaz (2006), was undertaken. All authors discussed the proposed themes and a further iterative process of analysis and abstraction took place to arrive at the final themes. To ensure rigour, memos were developed in NVivo to document reflections during the process of recruitment, data collection and analysis as well as all the decisions made by the research team (Charmaz 2006). Being an insider contributed to the establishment of rapport with the participants, whilst holding the middle ground during the interviewing, interpretation and analysis of the data (Burns et al. 2012) was achieved by having self-consciousness and holding regular meetings with the research team (coauthors) who only read the de-identified data and so were considered as outsiders (one being an obstetrician). Direct quotes have been used to illustrate the findings with a number after each quote to denote the participant.

Box 1 Questions asked in the semi-structured in-depth interviews

1. Can you tell me about your story of being involved with vasa praevia?

2. (if the midwife was involved in more than one case including antenatal diagnosis) Can you tell me a bit more about the woman who was not diagnosed in pregnancy?

3. How was the experience for you?

4. What was the woman's reaction?

5. How was the baby when born?

6. How was it like for the others who were involved in that case?

\section{Findings}

Twenty midwives agreed to participate in the study. Of those, 12 had cared for women who had a neonatal death $(n=5)$, near-miss $(n=6)$, or both neonatal death and near-miss $(n=1)$ in circumstances where no antenatal diagnosis of vasa praevia had been made. 
Javid N, Hyatt J, Homer CSE. (2019) The experience of vasa praevia for Australian midwives: A qualitative study. Women and Birth. 32 (2), pp. 185 - 192.

The focus of this paper is on the experiences of these 12 midwives. The midwives were from New South Wales $(n=7)$, Victoria $(n=2)$, or Western Australia $(n=3)$, and from nine different hospitals, public $(n=8)$, private $(n=3)$, or a mix of both public and private $(n=1)$. Midwives ranged in age from 26 to 65 years with average years of experience in midwifery being 19 years (max 33 years). Half of the midwives held senior positions including clinical midwife consultants $(n=3)$, clinical midwife specialists $(n=2)$, and clinical midwife educator $(n=1)$. One midwife worked in caseload midwifery. Majority of the midwives worked in the metropolitan $(n=10)$ hospitals including six large tertiary hospitals, and two worked in large regional hospitals.

The over-arching theme 'devastating and dreadful experience' describes the experience of midwives caring for women who had an unexpected neonatal death or 'near-miss' event following an emergency caesarean section due to vasa praevia. Midwives used words such as 'dreadful', 'destroying', 'very traumatic', 'very stressful', 'terrible', 'catastrophic' and 'disaster' when re-telling the story of the event. The over-arching theme included two inter-related categories that described the personal impact and professional processes (Figure 6). The personal impacts of this unexpected event included feeling scared, shocked, guilty, and described how the experience took its toll. Professional processes included the experience of working in organised chaos, feeling for the parents, finding communication to be hard, and doing their best to save the baby.

\subsection{Personal impacts}

Caring for women with undiagnosed vasa praevia during labour and birth had a profound emotional impact on the midwives. Three sub-themes of 'feeling scared', 'being shocked', and 'taking its toll' highlighted this personal impact.

\subsubsection{Feeling scared}

The experience was 'scary' for almost all midwives. They were scared that the baby may die before birth while organising the emergency CS, as well as after the birth if the baby was born in poor condition. The uncertainty made them scared as explained here: 'it 
Javid N, Hyatt J, Homer CSE. (2019) The experience of vasa praevia for Australian midwives: A qualitative study. Women and Birth. 32 (2), pp. 185 - 192.

was pretty scary only because no-one knew what the diagnosis was or why it had happened at the time'. Midwives felt 'scared' as they thought they would be held partly responsible for the baby's death. It was also scary to know that vasa praevia did not have any signs or symptoms. For example, one midwife expressed:

We didn't have any evidence, that's the most scary part of it, because usually with vasa praevia you expect some trickles... The clot was so massive. (M2)

Some midwives felt that other maternity care providers were scared too as one midwife explained:

It was scary for everyone. I remember that people from theatre were coming up and they wanted to see the baby and what happened with the baby... we were devastated. Although we acted so quickly and it happened in the hospital, we couldn't- it was a big vessel... a big huge vessel that was compromised. (M5)

Midwives involved in the near-miss events felt scared, as one midwife explained her feelings while they were going for CS: 'in my head the whole time I was thinking, don't let this baby die'. Fear of losing the baby continued after the baby was born. For example, one midwife explained her feeling while reviving a baby born with no heart rate from a woman who had vaginal bleeding due to ruptured vasa praevia after spontaneous rupture of membranes:

It was pretty scary... we were resuscitating and I thought there's just no way this baby is going to survive... [the baby] was basically grey and obviously floppy... had no foetal heart for that long... There just seemed to be no signs of life whatsoever. ... I literally just thought it came out dead... but as soon as they [the neonatologists] started giving blood [the baby] started pinking up and they found a heartbeat. (M3)

Midwives were scared as they recognised that the babies were at risk of dying.

\subsubsection{Being in shock}


Javid N, Hyatt J, Homer CSE. (2019) The experience of vasa praevia for Australian midwives: A qualitative study. Women and Birth. 32 (2), pp. 185 - 192.

Midwives were shocked before and after the birth, and regardless of the outcome for the baby. Some were 'in shock' by the baby's poor condition after emergency CS and 'just couldn't believe it' when the baby died. Complications were unexpected as the woman's pregnancy was 'normal' and the baby was 'healthy'. Midwives highlighted that 'everything was perfect and then at the last minute everything went wrong' when the baby deteriorated and died'.

It was devastating... After that we had to record everything... We had to write down everything what happened - and we just were blank. I mean we just couldn't put everything together. (M5)

Everybody was devastated...It's like any unexpected loss.... The baby was very pale, floppy and hypovolemic... It was only about 25 minutes from the time of a decision to go to theatres, but that was too long for that baby. (M7)

Midwives involved in the neonatal near-miss were also shocked by the baby's condition at birth, as well as other clinicians involved in the care. For example, one midwife explained that 'it was a disaster for everyone involved- the theatre staff, doctors, anaesthetist'.

I had no idea what was happening. Neither did the obstetrician... I think he was pretty shocked actually when he discovered looking at the placenta. He was pretty kind of amazed at sort of what the diagnosis was too. (M3)

Midwives were shocked with the diagnosis of vasa praevia. They were 'shocked' that vasa praevia had not been diagnosed during pregnancy expressing that there was 'no indication at all' on the ultrasound report. Some midwives reported fetal bradycardia, while others were 'surprised' that there was no predicting sign on the cardiotocograph (CTG).

She had a perfectly normal trace to just nothing. It just dropped completely out. There was just no fetal heart. There wasn't even an acceleration beforehand. (M3) 
Javid N, Hyatt J, Homer CSE. (2019) The experience of vasa praevia for Australian midwives: A qualitative study. Women and Birth. 32 (2), pp. 185 - 192.

Statements like 'vasa praevia is so uncommon that people don't think about it', and 'it's not on the radar' demonstrate that most midwives did not think about vasa praevia as the reason for fetal distress and vaginal bleeding while providing intrapartum care, and 'did not know what the diagnosis was' until 'they checked the placenta'.

Midwives were shocked with the diagnosis of vasa praevia, the lack of antenatal diagnosis or warning, by the suddenness and unpredictable nature of the fetal haemorrhage, and how quickly the baby moved from being healthy to being hypoxic and potentially dying.

\subsubsection{Feeling guilty}

Midwives reported that women mostly had 'low risk' pregnancy and 'nothing in the ultrasound' to suggest a problem, and hence felt guilty when an adverse outcome occurred. Although midwives recognised that the vasa praevia was undiagnosed, a sense of 'guilt' and 'blame' was evident. Midwives reflected that they might have 'done something wrong', 'missed something', 'could have done better' or were 'responsible for what happened'. Sentiments like 'what could I have done to stop this from happening' and 'should the baby had come out sooner' display the sense of 'guilt' when the baby was born in a poor condition and/or died. The sense of guilt was present even when the baby survived, but it was more significant among those who cared for women whose babies died. For example:

Everyone felt guilty about it ... because you are responsible for that family, for that baby. And what you've done to prevent this? We didn't do anything to be honest, because we couldn't. If we knew she would have had an elective CS. (M2)

It was dreadful... you are really concerned and wonder what you could have done better when the baby was born quite unwell ... especially when we watched the fetal heart rate pattern for quite a while thinking she was going to progress quickly and she didn't. So you reflect on whether you should have escalated earlier to push for a caesar earlier. (M1) 
Javid N, Hyatt J, Homer CSE. (2019) The experience of vasa praevia for Australian midwives: A qualitative study. Women and Birth. 32 (2), pp. 185 - 192.

Midwives felt 'distraught' and guilty even when it had only taken a short time to recognise that there was a problem and act upon it. When the midwife knew the woman before the labour, the sense of 'guilt' was strong as the midwife reflected that she was responsible for the woman's pregnancy:

Well I felt for myself obviously ... I felt that I'd missed something. Maybe I should have done something more during pregnancy. Especially because I was responsible for her pregnancy... I always take it as a shame on myself. (M4)

The stories of midwives highlighted the feelings of guilt and self-blame during these experiences. 
Javid N, Hyatt J, Homer CSE. (2019) The experience of vasa praevia for Australian midwives: A qualitative study. Women and Birth. 32 (2), pp. 185 192.

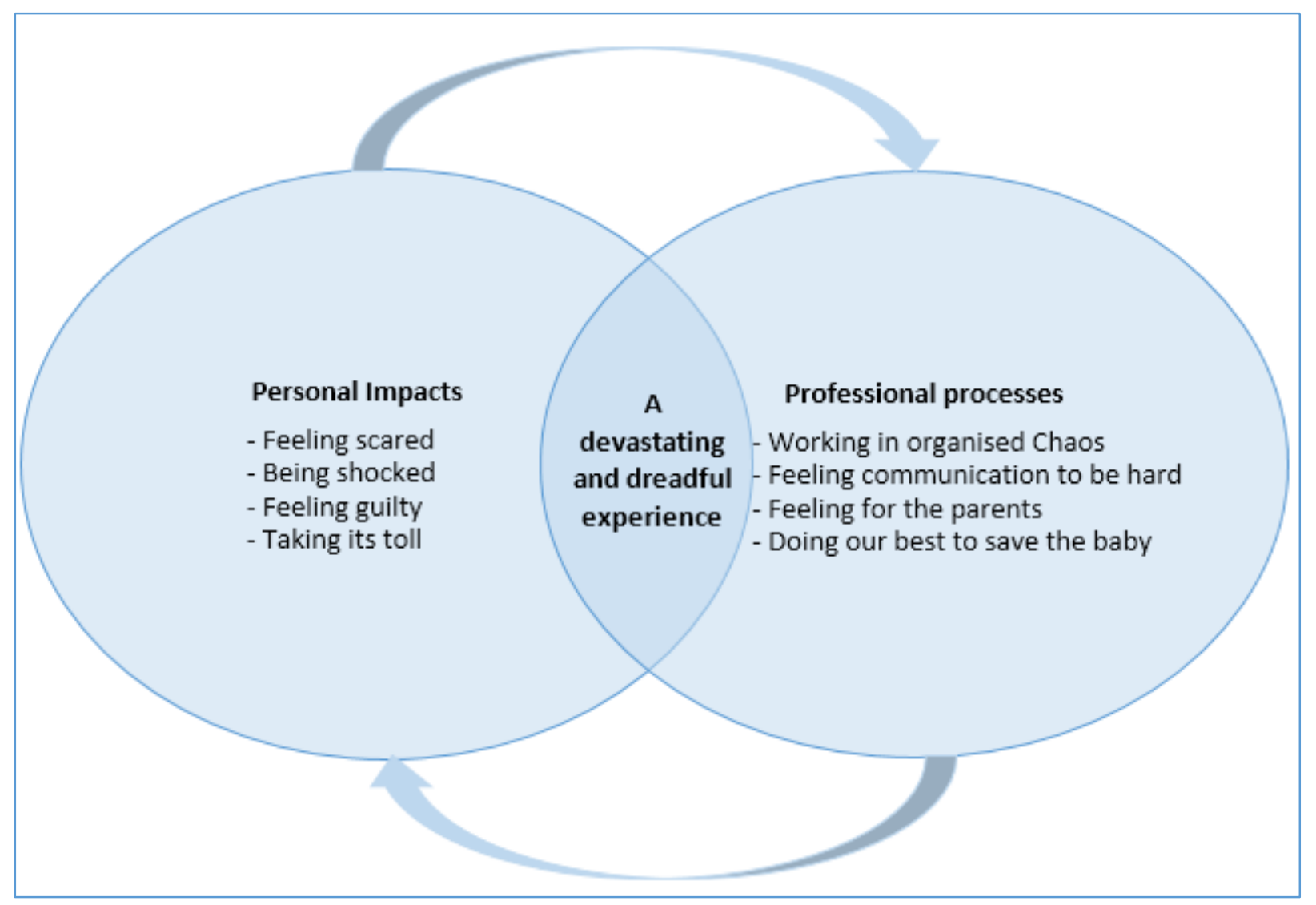

Figure 1 Experience of midwives caring for women with undiagnosed vasa praevia during labour and birth 
Javid N, Hyatt J, Homer CSE. (2019) The experience of vasa praevia for Australian midwives: A qualitative study. Women and Birth. 32 (2), pp. 185 - 192.

\subsubsection{Taking its toll}

The personal impact of the events was long-lasting. Midwives could 'remember everything', 'the room, where she was', and 'the day' 'very clearly'. The event took its toll on the midwives and left 'a mark' for the rest of their lives. For instance, one midwife expressed:

When it does happen to you, you do remember it... I still remember that case... so long time ago, now but I still remember it very clearly. (M1)

One midwife described how the event impacted herself as well as her midwifery colleague who was the primary care giver for the woman who experienced neonatal death. She explained:

She was devastated... She always - she's passing all the big cases or anything that will happen. She's really strong and had been doing some life coaching and has been reading a lot of books and she's a really positive person, but that affected her really badly at that time. It was really hard for everyone that was in the unit. (M5)

The experience affected midwives' view of the mid wifery profession. They acknowledged that they 'still enjoy midwifery' and 'working in midwifery is really good' and 'rewarding most of the time'. However, they mentioned 'that's the name of the game' that midwifery was not always about having 'a joyful' normal labour and birth, and a healthy baby, highlighting that 'there is a lot of pain' in midwifery and 'nasty things can happen'. The emotional impact of the event was not limited to the midwives, and took its toll on the obstetricians as well, as one midwife stated: 'even the obstetrician was really upset from being in the medical field'. Another midwife said that the senior registrar who cared for the woman discontinued obstetrics.

After that case this senior registrar, you know year after she finished, she never did obstetrics, because everything came back to her... She was in the last year. She was about to finish. She never did obstetrics. She just did gynaecology. (M2) 
Javid N, Hyatt J, Homer CSE. (2019) The experience of vasa praevia for Australian midwives: A qualitative study. Women and Birth. 32 (2), pp. 185 - 192.

Some midwives felt they were 'judged' and 'blamed' for what happened and that this took its toll. For example, one midwife reported that she had to defend herself as she felt that the consultant obstetrician blamed her for the baby's death and wanted her 'to be responsible for what happened'. Another midwife reported that her practice was investigated when she was talking about a woman who 'nearly lost her baby because of undiagnosed vasa praevia'. Although the woman and her baby survived, her husband made a legal complaint in relation to the doctors and midwives in charge of her care. The complaint was that the vasa praevia was not diagnosed during pregnancy and the woman was 'allowed to labour'.

These accounts demonstrate how the suddenness and unpredictable nature of ruptured fetal vessels in vasa praevia, a fast deterioration of the baby towards death, and efforts of multidisciplinary team (midwives, obstetricians, anaesthetics, and neonatologists) to save the baby's life 'had a huge impact' on the personal health of the midwives.

\subsection{Professional processes}

The professional work of the midwives was affected by their experiences. The four themes of 'working in chaos', 'feeling for the parents', 'finding communication to be hard', and 'doing our best to save the baby' in this category describe how the professional work of midwives was impacted by the ruptured vasa praevia.

\subsubsection{Working in organised chaos}

'Working in organised chaos' describes the process of caring for women with ruptured vasa praevia. This was because the midwives did not know what the problem was or why it had happened, but they knew it was an emergency. Working in organised chaos was 'very rushed''it was like go go go- literally run to theatre, baby was out'. They needed 'the whole team on board - the anaesthetist, the doctors and the paediatricians' in the operating theatre in a very short period of time. One midwife described this process clearly:

It was sort of like organised chaos. We kind of knew we had to get the baby out but we didn't really know why so we just kind of went for it and I didn't really have time to think about it. ... we delivered the baby probably in about 12 minutes from the time of 
Javid N, Hyatt J, Homer CSE. (2019) The experience of vasa praevia for Australian midwives: A qualitative study. Women and Birth. 32 (2), pp. 185 - 192.

me discovering that [vaginal bleed] to the baby coming out... There were two or three neonatologists directing people what to do. (M3)

For some midwives, 'working in organised chaos' included challenges in getting access to emergency facilities or resources including operating theatre and blood. One midwife reported that although the decision was made to do an emergency CS, 'the theatres were all engaged'.

It was quite traumatic for everyone... I was pushing the bed in the corridor; we didn't have a definite theatre. So, I was passing by the theatre and I saw one of the anaesthetists. I said we need your help, please find a theatre immediately, we need to get this baby out as soon as we can. (M12)

Sometimes the 'chaos' was less organised due to being an emergency. For example, one midwife explained a delay in getting blood for the baby from the pathology for a woman who was transferred to her hospital for emergency CS. The CS was undertaken within 10 minutes of arrival, but there was no medical record number for the baby. The pathology department had difficulty in understanding the reason that $O$ negative blood was ordered. Three midwives told their painful stories of how babies died after emergency CS and aggressive resuscitation, as decisions were made to 'just stop the resuscitation' and 'allow the nature to take its course' because the babies were 'already damaged with the blood loss'.

'Working in organised chaos' meant doing multiple activities [eg. getting access and rushing to theatre, getting the neonatal team to the theatre, getting blood from the blood bank, doing the blood transfusion in the theatre, transferring the baby to the neonatal intensive care unit (NICU)] all within an extremely short period of time. It also included dealing with delays and difficulties in accessing these resources.

\subsubsection{Feeling for the parents}

Even through the experience was personally distressing; midwives recognised that on a professional level there was a lot to deal with. Midwives 'felt for the parents' as they observed 
Javid N, Hyatt J, Homer CSE. (2019) The experience of vasa praevia for Australian midwives: A qualitative study. Women and Birth. 32 (2), pp. 185 - 192.

the impact on the families, describing that the women were in 'shock', 'disbelief', 'denial', 'shell-shocked', 'very sad', 'distraught', and 'couldn't believe it'. For example:

She [woman] was in denial. I remember I walked in and she was cuddling the baby but wasn't crying. She looked shocked, the same as everyone else in the room. (M12)

All midwives acknowledged the loss of a baby to be a tragic event for all parents in any circumstance but felt that it was more traumatic because these women had no warning. For example, one midwife reported that parents were 'absolutely distraught' because the woman had had a normal antenatal course with previous uncomplicated pregnancies and births:

She was not expecting any issue until they saw the bleeding. Even then mum wasn't concerned that there was any problem, it took her a while to work out that she needed to have a caesarean... they were extremely shocked, understandably. (M9)

Similarly, midwives reported that families experienced 'trauma' even when the baby survived because their babies had to be aggressively resuscitated, and transferred to NICU, in some cases to other hospitals, for higher care. This made some midwives feel 'quite upset' for the women and their partners.

In describing the experiences of the families, the midwives reported that fathers were also 'distressed', 'upset, 'terrified', and 'shocked' not only for their babies but also for the woman. The midwives had to deal with these concerns as well. Fathers 'understandably' wanted to know 'what had happened'. For example, one midwife did not go to the operating theatre and stayed with the woman's partner to support him during the emergency CS by general anaesthetic. The midwife described dealing with his grief as well:

They explained to him that his wife was going to have a general anaesthetic, so the delivery could be done as quickly as possible. He was really really upset... He was crying. He was just terrified that his wife was going to die. That's what he was sort of saying that he was worried about her. (M11) 
Javid N, Hyatt J, Homer CSE. (2019) The experience of vasa praevia for Australian midwives: A qualitative study. Women and Birth. 32 (2), pp. 185 - 192.

Another midwife said that although she knew that the husband was 'in shock', but due to all the activity he had to be left alone while the woman was having an emergency CS.

She was obviously quite shocked and so was the husband... The husband was very emotional. He couldn't come into the theatre because she had to have a GA. So, he was kind of stuck on his own for a while. (M3)

Most midwives felt 'angry' about the outcome expressing that it could all be prevented. One midwife described this as:

Losing the baby and it doesn't matter whether it is number three or number five, it is a human being. Something that was preventable and not expected at all. We didn't have a sick baby to be born and it did upset everyone who was involved. (M12)

Midwives understood the women and their partners' concerns, trauma, loss and grief, and showed empathy for them.

\subsubsection{Finding communication to be hard}

Communicating with the women and their partners at different time points was challenging. This included before and after the emergency CS when the baby was born with poor condition, during resuscitation, and after the baby's death. While midwives understood that women needed to be informed, communicating this was not easy. Communication was hard when the decision was made to do emergency caesarean section because there was uncertainty about the diagnosis. Rushing to the theatre for an emergency CS while trying to explain the situation was very challenging, for example:

No-one knew what the diagnosis was or why it had happened at the time. It was quite scary and then having to tell her husband who couldn't come into the theatre what was going on was pretty challenging. (M3)

Communicating with the woman when there was a delay to do the emergency CS was difficult, as one midwife explained: 
Javid N, Hyatt J, Homer CSE. (2019) The experience of vasa praevia for Australian midwives: A qualitative study. Women and Birth. 32 (2), pp. 185 - 192.

Unfortunately, there was a delay and that added to everybody's distress... We wanted to stay calm and together and to keep mum not panicking. She kept saying what's happened. We needed to inform her. Her doctor explained that we are waiting for a vacant theatre. So, the stress level was really high. (M12)

Communicating with the women about the possible outcome of the baby before birth was challenging. For example, one midwife explained: 'I wasn't communicating with her there. I don't think that I've been beneficial to her to let her understand and realise that she was going to lose the baby'. Fathers also wanted to know about the outcome of their babies, as another midwife explained:

He just kept asking what happened? ... It was quite difficult because he was very distressed ... I didn't want to give him any false hope. (M11)

There were also challenges in relaying information to the women about the outcome of their babies as they woke up after general anaesthetic for CS, and hence were sometimes described as being 'pretty groggy and drowsy'. While women were in the operating theatres or recovery rooms, their babies may have been transferred to NICU. The information about the progress of their babies was given by their partners, NICU staff, or others.

Her partner was there for some of the resuscitation, so he was able to let her know what was going on.... one of the medical team went backwards and forwards keeping her up-to-date to what was happening. (M9)

Midwives reported that even the obstetricians involved in the care had difficulty talking to the women and their partners following the loss. One midwife who was caring for a woman whose baby died in theatre reported that her doctor did not know what to say to the woman after the baby died.

I couldn't talk, because I was upset ... because I knew the baby didn't make it. The baby died... I remember the obstetrician said 'how can I explain this to the family? What excuses I have here?' ... They couldn't make sense of how to say to the family. Unfortunately, I wasn't there when he went to talk to the family. (M2) 
Javid N, Hyatt J, Homer CSE. (2019) The experience of vasa praevia for Australian midwives: A qualitative study. Women and Birth. 32 (2), pp. 185 - 192.

Uncertainty about the diagnosis, and baby's survival as well as the need to work to save the baby's life affected the midwives' professional communication with the women and their partners.

\subsubsection{Doing our best to save the baby}

This theme describes the midwives' reflection of the events as they concluded their narratives. Midwives felt that 'every single person did their best. It was unfortunate that vasa praevia had not been picked up by ultrasound'. They accepted that death was 'just unavoidable', stating that ruptured vasa praevia was 'a natural cause for' adverse outcome. They 'could not prevent' death as 'it was unknown if the woman had vasa praevia'. Midwives reported that if they knew the woman had vasa praevia the woman 'wouldn't be labouring' and 'would just be having a caesarean'. Unfortunately, for some midwives, despite rushing to the theatre for an emergency CS and the enormous efforts of midwifery, obstetric and neonatal teams, efforts to save the baby's life failed because 'by that time the baby had been bleeding quite a bit', 'it was too late' and the baby was 'totally anaemic', 'unresuscitable', and 'exsanguinated really'.

In contrast, there was a sense of feeling 'lucky' in the accounts of all midwives when the babies survived the 'near-miss'. Almost all reported that those babies were 'quite unwell', 'had birth asphyxia' at birth, and had to have a wide range of resuscitation including cardiac compressions, emergency blood transfusions in the operating theatre, or neonatal therapeutic hypothermia. Midwives recognised that they were 'lucky' that they were 'working where there were lots of resources to support them'.

Most midwives had some kind of professional support and debrief from their colleagues and hospitals. One midwife, however, who was involved in a neonatal death, reported that 'the manager said to go home and that's it... I never had debriefing for that case'.

\section{Discussion}

This is the first qualitative study to describe the experience of midwives involved in a neonatal death or near-miss due to vasa praevia. The study highlights the profound emotional impact 
Javid N, Hyatt J, Homer CSE. (2019) The experience of vasa praevia for Australian midwives: A qualitative study. Women and Birth. 32 (2), pp. 185 - 192.

of the event on the midwives, which in turn influenced the professional care they were providing to the traumatised women and their partners simultaneously while they had to manage their own emotion.

Although this study reports on the experience of midwives caring for women with vasa praevia, the findings may be similar to other unexpected emergency obstetric conditions that may lead to perinatal or maternal mortality and morbidity.

Midwives in our study expressed feelings of shock and horror witnessing the (potentially) dying baby, as well as guilt, anger and ruminative thoughts after the event. This confirms findings of previous research reporting similar feelings following a perinatal loss (Beck, LoGiudice \& Gable 2015; Leinweber et al. 2017; McNamara et al. 2017; Schrøder et al. 2016; Sheen, Spiby \& Slade 2015; Wahlberg et al. 2017). These feelings have been shown to be associated with PTSD in midwives who were involved in traumatic birth due to perinatal or maternal death or near-miss in different countries including Australia (Leinweber et al. 2017), Sweden (Wahlberg et al. 2017), and the United Kingdom (UK) (Sheen, Spiby \& Slade 2015), and secondary traumatic stress in the United States (US) (Beck, LoGiudice \& Gable 2015). Psychosocial burden of traumatic birth including burn out, stress, and guilt were also reported among Danish midwives (Schrøder et al. 2016). Feelings of horror and guilt are major risk factors for developing PTSD (Leinweber et al. 2017; Wahlberg et al. 2017). We did not ask our participants about potential PTSD experiences however, this needs to be considered as a possibility and strategies may need to be put in place to address this eventually.

The accounts of the midwives in our study suggest that other maternity care providers including obstetricians may had also been negatively impacted by the events. Recent international studies report feelings of shock, guilt, self-blame, PTSD, and change of practice in obstetrician consultants involved in the traumatic birth and perinatal death (McNamara et al. 2017; Schrøder et al. 2016; Wahlberg et al. 2017). Future studies are needed to investigate the impact of perinatal death and near-miss due to ruptured vasa praevia on the obstetricians. 
Javid N, Hyatt J, Homer CSE. (2019) The experience of vasa praevia for Australian midwives: A qualitative study. Women and Birth. 32 (2), pp. 185 - 192.

Schrøder et al (2016) in their mixed method study with Danish midwives and obstetricians reported that feelings of guilt were more prevalent when the midwives or obstetricians perceived that the adverse outcome had been preventable. Several studies demonstrate that perinatal mortality and morbidity due to vasa praevia can be reduced if it is diagnosed antenatally and elective CS is performed prior to rupture of fetal vessels (Bronsteen et al. 2013; Oyelese et al. 2004; Sullivan et al. 2017). Oyelese et al. in a study of 155 women with vasa praevia reported that only $44 \%(41 / 94)$ of the babies born to women with no antenatal diagnosis of vasa praevia survived (30\% stillbirth and $26 \%$ neonatal death), compared to $97 \%$ fetal survival rate for babies born to women with antenatal diagnosis. The rate of neonatal blood transfusion was significantly higher (59\% compared to $3 \%$ ) in women with no antenatal diagnosis of vasa praevia (Oyelese et al. 2004). Similarly, in Australia, a national populationbased prospective study reported no perinatal deaths in 58 women with antenatal diagnosis of vasa praevia compared to $40 \%$ ( 2 in 5; one stillbirth and one neonatal death) in those who were not diagnosed during pregnancy (Sullivan et al. 2017). Among 58 women antenatally diagnosed, all had planned CS, 70\% were hospitalised, received cortico-steroids for fetal lung maturation, and had CS before 37 weeks gestation (Sullivan et al. 2017). Participants in our study reported that the adverse outcomes for these women could have been prevented if they knew women had vasa praevia and women were offered an elective CS, highlighting the concept of professional responsibility and safe maternity care (National Health Service England 2016).

Midwives in our study emphasised the grief and emotional impact of loss or witnessing emergency life-saving medical interventions on the parents. Yet, the impact of ruptured vasa praevia on the women and their families has attracted little attention from researchers. Our literature review found only one study with the women with vasa praevia which briefly described the devastating impact of this event (Javid et al. 2014). Larger studies are needed to provide a more representative description of the experience of women and their partners who have lost their babies due to vasa praevia. Nevertheless, the impact of perinatal death on women (due to other reasons) and importance of appropriate care following loss have been well described in recent years (Bakhbakhi et al. 2017; Ellis et al. 2016). Fathers or partners also experience negative psychological emotions due to traumatic birth, but their 
Javid N, Hyatt J, Homer CSE. (2019) The experience of vasa praevia for Australian midwives: A qualitative study. Women and Birth. 32 (2), pp. 185 - 192.

need for support from maternity care providers has received less attention (Elmir \& Schmied 2016). Some midwives in our study identified specifically that partners needed support.

The weight of professional responsibility, compassionate midwifery care (Ménage et al. 2017), as well as disturbed emotions and working in a chaotic situation influenced midwives' communication with the families during and immediately after the event. Communication with the parents in the time of perinatal mortality and morbidity has been demonstrated to be challenging, yet a key factor that has been shown to help parents during this difficult time (Ellis et al. 2016; Lemmon et al. 2016). Educational activities are needed to improve communication skills of midwives and other maternity care providers with parents during and after perinatal deaths and near-miss events (Bakhbakhi et al. 2017; National Health Service England 2016).

Witnessing traumatic birth (when the mother or baby is at risk of death or serious injury), may be associated with midwives ceasing to work in labour and birthing units for a period of time, changing their area of work, or leaving the midwifery profession permanently, according to the surveys conducted in Australia (Leinweber et al. 2017), Sweden (Wahlberg et al. 2017), UK (Sheen, Spiby \& Slade 2015), and USA (Beck, LoGiudice \& Gable 2015).

Midwives in our study recognised ruptured vasa praevia as a cause for the inevitable adverse outcome. They reflected on the positive aspects, doing their best to save the baby in order to cope with their emotional distress. They also perceived that midwifery and childbirth was not always about having a joyful normal birth, and a healthy baby, accepting the inevitability of some adverse outcomes. These strategies have been reported to build resilience in midwives (Crowther 2017). Nevertheless, all midwives highlighted the importance of antenatal diagnosis as a key factor that may improve perinatal outcomes.

Antenatal ultrasound diagnosis of vasa praevia is accurate (Ruiter et al. 2015), and needs to be confirmed during the third trimester (using transvaginal colour Doppler ultrasound) in women who had been identified with vasa praevia during the routine second trimester morphology ultrasound (RANZCOG 2016; RCOG 2011). RANZCOG currently recommends that women with the confirmed diagnosis of vasa praevia be admitted 'to a hospital with 
Javid N, Hyatt J, Homer CSE. (2019) The experience of vasa praevia for Australian midwives: A qualitative study. Women and Birth. 32 (2), pp. 185 - 192.

appropriate neonatal facilities from around 30 weeks of gestation' until birth by CS at 35 weeks gestation (RANZCOG 2016).

Screening all pregnant women for vasa praevia (universal screening) is not currently recommended internationally or nationally due to the cost associated with the rarity of the condition as well as lack of high quality data on the optimal management and best time of birth for women diagnosed with the condition (RANZCOG 2016; RCOG 2011). RANZCOG (2016) recommends screening women who have any risk factor for vasa praevia (targeted screening). A systematic review reported that $83 \%$ of the women with vasa praevia have at least one risk factor for vasa praevia (Ruiter et al. 2016). In 2017, Sullivan et al. reported that $95 \%$ of the women with confirmed diagnosis of vasa praevia at birth had one or more risk factors for vasa praevia (Sullivan et al. 2017). If targeted screening is implemented, it is possible that $5-17 \%$ of the women with vasa praevia may not be identified. Hence some midwives may encounter a women with undiagnosed vasa praevia during labour who may experience rupture of a vasa praevia vessel. The results of this study have significant implications for maternity care providers, educators and policy makers. Raising awareness regarding risk factors for vasa praevia to ensure implementation of targeted screening, possibility of encountering a woman with undiagnosed vasa praevia during labour and birth, and providing appropriate care in these situations may improve quality of maternity care for women with this serious condition.

Supporting midwives personally and professionally is imperative after an adverse event to improve emotional well-being (Crowther 2017; Sheen, Spiby \& Slade 2015). Yet, in the aftermath of traumatic events, some midwives reported lack of support, or low satisfaction with the support they were provided - describing it to be insufficient or inappropriate (Crowther 2017; Pezaro et al. 2016; Wahlberg et al. 2017). Although interventions such as mindfulness programs, work-based resilience workshops with mentoring programs, and clinical supervisions have been reported to support the psychological wellbeing of midwives and/or midwifery students, there is a lack of high-quality interventions that are designed specifically to support midwives (Pezaro, Clyne \& Fulton 2017). Midwives due to the nature of their work have close relationships with women, which may increase the risk of vulnerability (Beck, LoGiudice \& Gable 2015; Sheen, Spiby \& Slade 2015). Developing 
Javid N, Hyatt J, Homer CSE. (2019) The experience of vasa praevia for Australian midwives: A qualitative study. Women and Birth. 32 (2), pp. 185 - 192.

interventions that are non-judgmental, confidential, anonymous, and accessible to support midwives' emotional well-being may increase retention in the midwifery workforce and subsequently women's satisfaction of maternity care and safety of maternity services (Pezaro et al. 2016; Sheen, Spiby \& Slade 2015).

\subsection{Limitations}

Our study has a number of limitations. As in all qualitative studies, our findings cannot be generalised to all midwives in Australia or other countries. Midwives were self-selected and may be those with extreme experiences. However, there may have been other midwives who had similar or worse experiences but did not participate as they may have thought that retelling their stories during an interview may be stressful. Another limitation is recall bias, as midwives were narrating their stories. Nevertheless, midwives in our study emphasised that they clearly remembered the details of the events. The strength of our study is that this is the first qualitative description of the experience of midwives involved in the care of women with undiagnosed vasa praevia, providing an important in-depth contribution to the international discussion regarding vasa praevia, and more broadly to traumatic birth, and perinatal death.

\section{Conclusion}

This study provides an in-depth knowledge regarding the traumatic impact of ruptured vasa praevia on the personal and professional wellbeing of the midwives, even when the baby survived the 'near-miss'. The narratives highlight the challenges maternity care providers may encounter caring for women during labour and birth whose vasa praevia was not diagnosed during pregnancy, pointing to the need for antenatal diagnosis of vasa praevia in order to improve perinatal outcomes. Perinatal confidential inquiries should include neonatal nearmiss to better inform health policy.

Midwives are in the fore front of providing care to women during pregnancy, labour and birth. Providing ongoing formal education regarding rare obstetric emergencies, communication skills in the context of perinatal mortality and morbidity, as well as personal self-care and resilience will empower midwives to deliver high quality safe maternity care, and may increase midwifery retention. Midwives should be continually supported and adequately 
Javid N, Hyatt J, Homer CSE. (2019) The experience of vasa praevia for Australian midwives: A qualitative study. Women and Birth. 32 (2), pp. 185 - 192.

prepared to cope with traumatic events. Further research with midwives and obstetricians is needed to develop a toolkit for optimising management of ruptured vasa praevia, and to identify the barriers and facilitators for the antenatal diagnosis of vasa praevia.

\section{Conflicts of interest}

Authors claim no conflicts of interest.

\section{Funding}

The lead author was funded by Doctoral Scholarship from the University of Technology Sydney.

\section{Acknowledgments}

We thank the midwives who participated in this study for their time and generosity in sharing their experiences with us. 
Javid N, Hyatt J, Homer CSE. (2019) The experience of vasa praevia for Australian midwives: A qualitative study. Women and Birth. 32 (2), pp. 185 - 192.

\section{References}

1. Sullivan EA, Javid N, Duncombe G, Li Z, Safi N, Cincotta R, et al. Vasa Previa diagnosis, clinical practice, and outcomes in Australia. Obstetrics \& Gynecology. 2017;130(3):591-8.

2. Oyelese $Y$, Catanzarite V, Prefumo F, Lashley S, Schachter M, Tovbin Y, et al. Vasa previa: the impact of prenatal diagnosis on outcomes. Obstetrics \& Gynecology. 2004;103(5, Part 1):937-42

3. Bronsteen R, Whitten A, Balasubramanian M, Lee W, Lorenz R, Redman M, et al. Vasa previa: clinical presentations, outcomes, and implications for management. Obstetrics \& Gynecology. 2013;122(2, PART 1):352-7.

4. Ruiter L, Kok N, Limpens J, Derks J, De Graaf I, Mol B, et al. Systematic review of accuracy of ultrasound in the diagnosis of vasa previa. Ultrasound in Obstetrics \& Gynecology. 2015;45(5):516-22.

5. Ruiter L, Kok N, Limpens J, Derks J, Graaf I, Mol B, et al. Incidence of and risk indicators for vasa praevia: a systematic review. BJOG: An International Journal of Obstetrics \& Gynaecology. 2016;123(8):1278-87.

6. RANZCOG. Vasa praevia( C-Obs 47). Royal Australian and New Zealand College of Obstetricians and Gynaecologists; 2016.

7. RCOG Green-Top Guideline No 27. Placenta praevia, placenta praevia accreta and vasa praevia: Diagnosis and management: Royal College of Obstetricians and Gynaecologists, 2011.

8. Javid N, Sullivan EA, Halliday LE, Duncombe G, Homer CS. "Wrapping myself in cotton wool": Australian women's experience of being diagnosed with vasa praevia. BMC Pregnancy \& Childbirth 2014; 14: 318.

9. Beck CT, LoGiudice J, Gable RK. A mixed-methods study of secondary traumatic stress in certified nurse-midwives: shaken belief in the birth process. Journal of Midwifery \& Women's Health 2015; 60(1): 16-23.

10. Leinweber J, Creedy DK, Rowe H, Gamble J. Responses to birth trauma and prevalence of posttraumatic stress among Australian midwives. Women and Birth 2017; 30(1): 40-5.

11. Schrøder K, Jørgensen JS, Lamont RF, Hvidt NC. Blame and guilt-a mixed methods study of obstetricians' and midwives' experiences and existential considerations after involvement in traumatic childbirth. Acta Obstetricia et Gynecologica Scandinavica 2016; 95(7): 735-45.

12. Wahlberg A, Andreen Sachs M, Johannesson K, Hallberg G, Jonsson M, Skoog Svanberg A, et al. Post-traumatic stress symptoms in Swedish obstetricians and midwives after severe obstetric events: a cross-sectional retrospective survey. BJOG: An International Journal of Obstetrics \& Gynaecology. 2017;124(8):1264-71.

13. Sheen K, Spiby H, Slade P. Exposure to traumatic perinatal experiences and posttraumatic stress symptoms in midwives: prevalence and association with burnout. International Journal of Nursing Studies 2015; 52(2): 578-87.

14. Sandelowski M. Focus on research methods-whatever happened to qualitative description? Research in Nursing and Health 2000; 23(4): 334-40.

15. AlHW. Australia's mothers and babies 2013-in brief. Perinatal statistics series no. 31. Cat. no. PER 72. Canberra: AlHW, 2015.

16. Drabble L, Trocki KF, Salcedo B, Walker PC, Korcha RA. Conducting qualitative interviews by telephone: Lessons learned from a study of alcohol use among sexual minority and heterosexual women. Qualitative Social Work 2016; 15(1): 118-33.

17. Burns E, Fenwick J, Schmied V, Sheehan A. Reflexivity in midwifery research: the insider/outsider debate. Midwifery 2012; 28(1): 52-60.

18. Charmaz K. Constructing grounded theory: A practical guide through qualitative research. SagePublications Ltd, London 2006. 
Javid N, Hyatt J, Homer CSE. (2019) The experience of vasa praevia for Australian midwives: A qualitative study. Women and Birth. 32 (2), pp. 185 - 192.

19. Braun V, Clarke V. Using thematic analysis in psychology. Qualitative Research in Psychology 2006; 3(2): 77-101.

20. McNamara K, Meaney S, O'Connell O, McCarthy M, Greene R, O'Donoghue K. Healthcare professionals' response to intrapartum death: a cross-sectional study. Archives of Gynecology and Obstetrics 2017; 295(4): 845-52.

21. England NHS. National Maternity Review. Better Births. Improving outcomes of maternity services in England. A Five Year Forward View of maternity care; 2016. [cited 2017 August 15]. Available from: https://www.england.nhs.uk/wp-content/uploads/2016/02/nationalmaternity-review-report.pdf.

22. Bakhbakhi D, Burden C, Storey C, Siassakos D. Care following stillbirth in high-resource settings: Latest evidence, guidelines, and best practice points. Seminars in Fetal \& Neonatal Medicine 2017; 22(3): 161-6.

23. Ellis A, Chebsey C, Storey C, Bradley S, Jackson S, Flenady V, et al. Systematic review to understand and improve care after stillbirth: a review of parents' and healthcare professionals' experiences. BMC pregnancy and childbirth. 2016;16(1):16.

24. Elmir R, Schmied V. A meta-ethnographic synthesis of fathers' experiences of complicated births that are potentially traumatic. Midwifery 2016; 32: 66-74.

25. Ménage $D$, Bailey E, Lees $S$, Coad J. A concept analysis of compassionate midwifery. Journal of Advanced Nursing 2017; 73(3): 558-73.

26. Lemmon ME, Donohue PK, Parkinson C, Northington FJ, Boss RD. Communication challenges in neonatal encephalopathy. Pediatrics 2016: e20161234.

27. Crowther S. Resilience and Sustainability amongst maternity care providers. In: Thomson G, Schmeid V, Editors. Psychosocial Resilience and Risk in the Perinatal Period: Implications and Guidance for Professionals ; Taylor \& Francis; 2017.p. 185.

28. Pezaro S, Clyne W, Turner A, Fulton EA, Gerada C. 'Midwives Overboard!'Inside their hearts are breaking, their makeup may be flaking but their smile still stays on. Women and Birth 2016; 29(3): e59-e66.

29. Pezaro S, Clyne W, Fulton EA. A systematic mixed-methods review of interventions, outcomes and experiences for midwives and student midwives in work-related psychological distress. Midwifery 2017; 50: 163-73. 